\title{
Social Cash Transfers and Household Welfare: Evidence from Zambia's Oldest Scheme
}

\author{
Gelson Tembo ${ }^{1}$, Nicholas Freeland ${ }^{2}$, Bernadette Chimai ${ }^{1} \&$ Esther Schüring ${ }^{3}$ \\ ${ }^{1}$ Department of Agricultural Economics, University of Zambia, Lusaka, Zambia \\ ${ }^{2}$ MASDAR International Consultants, Reading, UK \\ ${ }^{3}$ Department of Social Security Studies, Bonn-Rhein-Sieg University of Applied Sciences \\ Correspondence: Gelson Tembo, Department of Agricultural Economics, The University of Zambia, P.O. Box 32379, \\ Lusaka, Zambia.
}

Received: January 19, 2014 Accepted: February 10, 2014 Available online: February 22, 2014

doi:10.11114/aef.v1i1.354

URL: http://dx.doi.org/10.11114/aef.v1i1.354

\begin{abstract}
Social cash transfers (SCTs) are considered a priority in least-developed countries, where the gap between the need for basic social protection and existing provisions is greatest. This study represents one of the first comprehensive treatments of the impact of social cash transfers in low-income sub-Saharan Africa, and the first for Zambia's oldest SCT scheme. The results, based on propensity score matching and fully efficient odds-weighted regression, and data from the Kalomo SCT pilot scheme, confirm positive SCT effects on per capita consumption expenditure. We also discover threshold effects with SCT mostly impacting food expenditure among poorer beneficiary households and non-food expenditure among wealthier beneficiaries.
\end{abstract}

Keywords: Social cash transfers, impact, consumption expenditure, propensity score matching, odds-weighted regression

JEL codes: C14, C21, D63, I38.

\section{Introduction}

Poverty reduction is of concern in countries that have the majority of their citizens living in poverty. Most strategies to reduce poverty aim to provide economic opportunities to the poor and to mobilize their productive potential. However, households that lack the necessary human and other forms of capital to participate in these programs are excluded from such poverty-reduction efforts. This sub-group of the poor has been the target of social protection interventions such as food aid, input support, asset distribution, and social cash transfers (SCTs). SCTs have become increasingly popular because of their inherent flexibility in helping with the target households' varied needs (Commission for Africa 2005). SCTs have also been known to lead to investment in productive enterprises that may lead to permanent welfare improvements for beneficiaries (Gertler, Martinez \& Rubio-Codina, 2006) as well as their communities (Angelucci and De Giorgi, 2009; Wietler, 2007). ${ }^{1}$

SCT programmes, with conditionality attached, are quite well-established in many Latin American countries, such as Brazil, Mexico, and Honduras. Non-contributory pension schemes are rapidly expanding and have taken root in a number of countries in Asia, such as China, India, Bangladesh, and Nepal; and southern Africa (South Africa, Namibia, Botswana, Lesotho, and Mauritania). The concept of regular and reliable assistance in cash is relatively new in most other sub-Saharan African countries. A few, such as Ethiopia, Malawi, Mozambique and Zambia, have piloted small-scale social assistance programmes. In Zambia, pilot SCT schemes have been in existence since 2003 with the primary aim to reduce extreme poverty among the poorest households with insufficient or no labour capacity. From the maiden pilot scheme in Kalomo in 2003, SCT schemes have since spread to 18 more districts and preparations are under way to add another 31 (see Section II).

Although a number of studies have been conducted on different aspects of the oldest SCT scheme, none have been

\footnotetext{
${ }^{1}$ See Tabor (2002) for comprehensive characterization, advantages and challenges of social cash transfers (SCTs) in both developed and developing countries.
} 
designed to measure the schemes' impact on household welfare in a scientifically robust way. An initial impact evaluation on the Kalomo pilot scheme that followed beneficiary households for a year, found improvements in a number of indicators, including school enrolment rates (by 3 percent), nutrition (both quantity and quality of meals), asset endowments, ownership of small livestock, and self-perception of social status (Schüring, Michelo, \& Boonstoppel, 2007). However, this study lacked a control group and did not quantify the size of the impact. The lack of a control group proved particularly problematic as the pilot region was hit by a drought during the evaluation year. Rigorous impact studies are a valuable source of lessons for subsequent project design and roll-out and provide an evidence base with which to solicit political will.

This study uses survey data from Zambia's oldest scheme, Kalomo, to determine the impact of SCTs on household welfare. To the best of our knowledge, this study represents one of the first comprehensive treatments of the impact of SCT programmes in low income countries of Sub-Saharan Africa. Recent SCT impact evaluation work in Zambia has focused on the more recent schemes such as the Monze SCT scheme (Handa et al., 2012; Seidenfeld et al., 2011) and the Child Grant Program (Handa et al., 2013a; Handa et al., 2013b; Daidone et al., 2013). No such study has been done on the oldest SCT program in Zambia. Moreover, neither the Monze model nor the CGP model is identical in design and/or implementation to the Kalomo model. The Monze program, while using the same inclusive targeting mechanism as the Kalomo program, experimented with educational and health conditionality on the beneficiaries Our paper contributes to the growing literature on the impacts of SCTs in Zambia and sub-Saharan Africa in general, extending the debate by measuring not only aggregate effects but also heterogeneous impact across household wealth strata.

A flexible and fully efficient version of propensity score matching (PSM) that uses odds-weighted regression analysis (Hirano, Imbens, \& Ridder, 2003) was used to estimate aggregate and heterogeneous impact on household consumption. Heterogeneous impact was estimated across wealth strata as defined by an asset wealth index generated using principal components analysis (Pritchett \& Filmer, 2003). The results indicate significant positive aggregate welfare effects. The impact was especially large with respect to non-food expenditure. This effect was greatest among asset non-poor households while food expenditure effects were greater among the poorer households. This seems to suggest, as expected, beneficiary households in general prioritize food items, and that there exist wealth threshold effects related to non-food expenditure effects.

The rest of the paper is organized as follows. Section II presents a brief overview of the pilot SCT schemes in Zambia and other African countries. The conceptual framework, on which the empirical models were based, is presented in Section III. Section IV presents the methods and procedures, followed by the empirical results in Section V, and summary and conclusions in Section VI.

\section{Social Cash Transfers in Africa and Zambia}

In the recent past, Social Cash Transfers (SCT) have gained popularity in many countries around the world, including Africa. Among the first African countries to adopt this concept were South Africa (Aguëro, Carter \& Woolard, 2006; Duflo, 2000; Case and Deaton, 1998) and Mozambique (Datt, Payongayong, Garret \& Ruel, 1997) and have since spread to several other countries in Sub-Saharan Africa (SSA) and beyond. Garcia and Moore (2012) show that there are few countries in Sub-Saharan Africa that have not taken the initiative. These programs have been shown to have desired impacts on aspects such as health (Lagande, Haines \& Palmer, 2009), food security (Miller et al., 2011), basic income (Standing, 2008) and poverty reduction (Barrientos \& Dejong, 2006).

Zambia has a population of 13 million, of which 64 percent and 54 percent are classified as poor and extremely poor, respectively (CSO, 2006). An estimated 200,000 households have been classified as being critically poor and incapacitated, characterised by high dependency ratios, elderly heads, and high incidences of Orphans and Vulnerable Children (OVCs) as high as 60 percent (Schüring, Michelo, \& Boonstoppel, 2007). Social cash transfers (SCTs) in Zambia started with a pilot scheme in Kalomo in 2003. By 2008, SCTs had been rolled out to four other districts: Chipata, Katete, Kazungula, and Monze. The Kalomo scheme pioneered the notion that the destitute with limited productive capacity comprise about 10 percent of Zambia's population. With the exception of Katete, the other three pilot schemes have been used systematically to test variants of the Kalomo model and to learn lessons for scaling up the cash transfers. ${ }^{2}$

SCTs were first identified in the 2005 Social Protection Strategy of the Ministry of Community Development, Mother

\footnotetext{
${ }^{2}$ This figure is empirically based. It constitutes the proportion of households found in the 2004 LCMS to have a per capita food consumption under $1400 \mathrm{kcal}$ per day and also lack able-bodied labor. This category of households is sometimes referred to as the 'nonviable' poor and tends to comprise elderly single-person households, elderly households with young children and orphans, households headed by HIV/AIDS widows, and households containing individuals with disabilities that make it very difficult for them to gain a living. A pilot survey conducted before Kalomo got under way apparently confirmed the validity of this proportion in a sample of the district population.
} 
and Child Health (MCDMCH) as one of the strategies for providing social assistance through the Public Welfare Assistance Scheme (PWAS). Since inception, the pilot SCT schemes have enjoyed the financial and technical support of a range of cooperating partners such as GIZ, DfID, CARE International, Irish Aid and UNICEF. In 2010, the Government of the Republic of Zambia (GRZ) and cooperating partners signed a memorandum of understanding (MOU) and a joint financing agreement to facilitate further scale-up of SCT programming from 5 to 15 districts over a period of 7 years. The MOU is a 10-year agreement, with initial funding of US $\$ 60$ million, subject to a major mid-term review and impact evaluation after the first three years of implementation (i.e. up to 2013). As part of this MoU, the Ministry of Community Development, Mother and Child Health (MCDMCH) has geographically targeted districts on the basis of incidence of extreme poverty.

Two types of SCT interventions were envisioned. First, an updated version of the community-based targeting (CBT) model intended to reach the population understood to be vulnerable was extended to five new districts (Chienge, Luwingu, Senanga, Serenje, and Zambezi). However, after much brainstorming with cooperating partners and consultants and an analysis of the 2006 Living Conditions Monitoring Survey (LCMS), the ministry later decided to change from CBT to categorical targeting (CT). This variant of the scheme has categories determined through a principal components analysis (PCA) and a poverty-based vulnerability index. The desired households, as determined by the PCA, are those that host orphaned and vulnerable children (OVC), among other things. Thus, this variant of the SCT program is sometimes referred to as the OVC model. The scheme is also referred to as the Multi-Category Program (MCP). ${ }^{3}$ Second, the child grant program (CGP) involving distributing SCTs to all mothers of children under the age of 5 was also established in five districts most affected by under- 5 mortality and extreme poverty (Chilubi, Kalabo, Kaputa, Milenge, and Shang'ombo). Reaching an estimated 50 percent of the households in each district, the scheme is intended to have a more intensive effect on vulnerable households in remote areas of deeply entrenched and widespread chronic poverty.

Table 1. Scale-Up Plan for the OVC/MCP and Child Grant Models

\begin{tabular}{lll}
\hline & \multicolumn{2}{l}{ Scale-up Districts by Program Type } \\
\cline { 2 - 3 } Year & OVC/MCP Model & Child Grant \\
\hline 2010 & Serenje, Luwingu, Zambezi & Kalabo, Kaputa, Shang'ombo \\
2012 & Chiengi & Chilubi \\
2013 & Senanga & Milenge \\
\hline
\end{tabular}

Source: Ministry of Community Development, Mother and Child Health (2011)

Table 1 summarizes the scale-up plan for two versions of the expanded scheme under the $2010 \mathrm{MoU}$. Implementation of the OVC/MCP and Child Grant Program (CGP) scale-ups has been staggered, with each of the two program variants first starting in three of the five districts and then scaling up to a fourth and a fifth district when certain performance indicators have been met. In 2010, the child grant scheme was successfully introduced in three of the five districts (Kaputa, Kalabo, and Shang'ombo), following a baseline survey conducted in November of the same year. ${ }^{4}$ The baseline survey for the other new SCT model was conducted in Luwingu and Serenje districts in November 2011. Implementation of the transfers in the two districts began shortly after that, in December 2011. As in Monze, the CGP and OVC schemes are also designed to facilitate comprehensive impact evaluation. Multiple follow-up surveys for the two new variants of the SCT intervention were planned for between 2012 and 2014.

The addition of CGP and OVC districts brought the total number of cash transfer beneficiaries in the country to 48,000 households. At the time of this paper, the number of beneficiaries had risen to 61,000 households across 19 districts. However, in 2014, due to significant impacts shown by impact evaluation studies, especially on the CGP (Handa et al., 2013a; Handa et al., 2013b; Daidone et al., 2013), and following an eight-fold increase in the Government budget allocated to the programme, the SCT interventions are being expanded to an estimated total of 189,000 recipients in 50 districts. This latest scale-up wave is using a substantially enhanced version of the inclusive model first pioneered by the oldest SCT scheme. The use of this type of targeting for the scale up was based on recommendations from a recent targeting assessment exercise (Carraro \& Marzi, 2013). Thus, the results of this study, based on the Kalomo scheme, provide valuable lessons going forward.

\footnotetext{
3 The ministry refers to this version of the cash transfer scheme as the inclusive model.

${ }^{4}$ However, owing to high security risks associated with the handling of the transfers by the Pay-Point Managers, there was a proposal to halt the scale-up to the new districts until a new payment mechanism was put in place. This necessitated the amendment to the Joint Financing Agreement.
} 


\section{Conceptual Framework}

Social cash transfers are motivated by extreme liquidity constraints that households experience during less productive stages in their life-cycle, during income shocks and situations of extreme poverty. These liquidity constraints are exacerbated by inherently imperfect credit markets (Gertler, Martinez, \& Rubio-Codina, 2006). Cash transfers can smoothen consumption and ensure that households do not fall below a critical threshold that is necessary to make a 'decent' living.

In Zambia, SCTs are to a great extent targeted at the poor and incapacitated households (Schubert \& Slater, 2006). Thus, the most anticipated effect of the SCT programmes in Zambia is increased welfare levels in the immediate and short terms but with long term implications. The idea is that better nourishment could improve the general condition, education and health outcomes as well asfuture productivity of the members of the incapacitated households and, hence, reactivate their latent potential to further improve their welfare both in the immediate and long terms. By providing some of the daily requirements, the SCT can free up time previously used to look for food, which could then be applied towards improving agricultural and non-agricultural production. School-age children may also be encouraged to enrol and, for those already enrolled, to increase their attendance rates, both with long term implications on welfare.

One of the most reliable measures of welfare in the literature is consumption expenditure. ${ }^{5}$ SCTs have significantly affected consumption levels of beneficiary households but also non-beneficiary households. Gertler, Martinez, \& Rubio-Codina (2006) found that beneficiary households of Mexico's OPORTUNIDADES programme (formerly called PROGRESA) were able to increase their consumption levels by as much as 34 percent through investment in productive activities. ${ }^{6}$ Angelucci \& De Giorgi (2009) provide a concise description of the design and structure of OPORTUNIDADES and demonstrate evidence of positive indirect effects on consumption levels of ineligible households, operating through informal insurance and credit markets. Sadoulet, de Janvry \& Davis (2001) estimate an income multiplier effect of 1.5-3.6 for the PROCAMPO cash transfer program in Mexico. These program effects on consumption do not necessarily have to be homogeneous across all beneficiary households. For example, relatively less poor households may have the relevant preconditions to use the SCTs to attain some of the outcomes quicker than their poorer counterparts. Conversely, poorer households may have had very low consumption levels to start with, leading to huge effects of the SCTs.

\subsection{Identification of Impact}

Identifying project-induced changes is often confounded by the fact that communities and individual households are inherently heterogeneous and participants are seldom selected randomly. Typically, projects use pre-determined criteria to locate their interventions and to identify the direct beneficiaries. This non-random selection of participants implies that the observed mean differences between project and non-project communities and households do not necessarily represent project impact (Ravallion, 2001).

Impact is commonly measured as the average treatment effect on the treated (ATT), defined as the expected value of the difference between the level of the outcome variable attained by participating households and that which they would have attained had they not participated in the project. $^{7}$ That is,

$$
A T T=E\left(Y_{t}^{1}-Y_{t}^{0} \mid w=1\right),
$$

where $Y_{t}^{1}$ is the outcome variable in period $t$ if household $i$ participated in the program, $Y_{t}^{0}$ is the outcome variable in period $t$ had household $i$ not participated in the treatment, and $w$ is the treatment indicator and is equal to 1 if the household is a participant and zero otherwise. ${ }^{8}$

A common challenge in impact evaluation is that only $Y_{t}^{1}$ or $Y_{t}^{0}$, and not both, is observed for any given community, household or individual, as the case may be. This is so because it is not possible for the same unit of study to be both a

\footnotetext{
${ }^{5}$ Although expenditure and income are supposed to be equivalent, the latter tends to be more volatile and prone to under-reporting bias

${ }^{6}$ In addition to immediate consumption and investment, evidence of increased savings has been found in some SCT programmes (Ravallion \& Chen, 2005).

${ }^{7}$ That is, confining ourselves to the definition of impact often referred to, in the literature, as the average treatment effect on the treated or ATT (Wooldridge, 2006; Ravallion 2001, 2003; Cameron \& Trivedi, 2005). See Imbens (2004), and Wooldridge (2002) for a comprehensive discussion of other treatment effects.

${ }^{8}$ Subscript $i$ has been suppressed to simplify notation.
} 
participant and a non-participant. Thus, with $w=1$ only $Y_{t}^{1}$ is observed and $Y_{t}^{0}$ is missing data. Estimation of the counterfactual constitutes the greatest challenge and a subject for much of the econometric literature on impact evaluation. In randomized experiments, $Y_{t}^{0}$ can be estimated from control communities and households. ${ }^{9}$ This makes it possible to attribute any systematic differences in the outcome variable between treated and control units to the program in question. In a non-randomized study, such as the one reported in this paper, the counterfactual has to be estimated from the controls through carefully chosen statistical tools.

\section{Methods and Procedures}

\subsection{Data and Data Sources}

This study uses cross-sectional survey data from the Kalomo SCT schemes in southern Zambia. The survey was conducted in 2007 by MASDAR International Consultants (MIC) and Palm Associates Limited (PAL). The sample was selected through two-stage stratified cluster sampling in which the primary sampling units (PSUs), the CWACs, were selected using probability proportional to size (PPS) and each household in either stratum (participants or comparison) in the selected PSU had an equal probability of being selected into the sample. ${ }^{10}$ Comparison households were selected from among households that had qualified to be in the programme based on the selection criteria but were left out only on account of the 10 percent cut-off point. The sample was designed to identify consumption impact at 80 percent power. With 88 percent response rate, the survey had a realized sample of 886 households, of which 45 percent were SCT beneficiaries.

\subsection{Impact Estimation}

Ravallion $(2001 ; 2003)$ characterizes the various methods used to estimate impact under quasi-experimental conditions. Although the SCT schemes targeted households in the top 10 percent on an implicit index of vulnerability, there were no consistent data on household orderings available at the project offices. ${ }^{11}$ However, due to the fuzziness of the cutoff point and the fact that the ranking process was abandoned half way (Hamoonga, 2007), it was possible to find matches between those in the programme and those just above the cutoff. Thus, impact was estimated by propensity score matching (PSM).

PSM presents a unique set of techniques for reconstructing an experimental environment out of a non-random, quasi-experimental design. The treatment or participation relationship was modeled through a probit framework with the aim to estimate the conditional probabilities of participation (given the observed characteristics), also known as the propensity scores (PS). The probit model was specified as:

$$
\operatorname{Prob}(w=1 \mid \mathbf{x})=\Phi\left(\alpha+\boldsymbol{\delta}^{\prime} \mathbf{x}+\varepsilon\right),
$$

where $w$ is a dichotomous variable equal to one if the household is an SCT beneficiary and zero otherwise, The Ministry offices had lists of beneficiaries and households that had qualified (based on targeting criteria) but were not included in the programme due to the 10 percent requirement. $\Phi$ is a standard normal cumulative distribution function (CDF); $\varepsilon$ is the error term; $\alpha$ and $\boldsymbol{\delta}$ are parameter and vector of parameters to be estimated; and $\mathbf{x}$ is a vector of household and community covariates used in the beneficiary selection process. Equation (2) was estimated using maximum likelihood (ML) procedures in Stata.

Beneficiary households in the scheme had been selected using a community-based approach in which a specific set of criteria were used (MCDSS and GTZ SSN 2007a; Watkins 2008). ${ }^{12}$ This list and information gathered by talking to MCDSS staff were used to specify $\mathbf{x}$. However, the final specification of $\mathbf{x}$ took cognizant of the variables' relative effects on the variance and bias of the estimates. Brookhart et al. (2006) contend, based on simulation experiments, that variables that are unrelated to the treatment but are related to the outcome should always be included as their inclusion

\footnotetext{
${ }^{9}$ Although randomization does not necessarily get rid of selection bias, it balances the bias between the treatment and comparison groups (Barker, 2000).

${ }^{10}$ Different administrative and geographic units are used to divide a district for the purpose of efficient and effective targeting and programme implementation. The CWACs and ACCs are the grassroots structures of the Public Welfare Assistance Scheme (PWAS), which is a national social welfare scheme responsible for coordinating all social welfare interventions down to the grassroots levels. Both the CWACs and ACCs are committees elected by members of their respective communities. As geographic units, the CWACs are used to define specific areas with a certain number of villages, and in turn the CWACs are nested within ACCs.

${ }^{11}$ This made it impossible to account for the ranking through appropriate statistical techniques, such as the regression-discontinuity design (RDD).

${ }^{12}$ Notice that there were differences in the combinations of variables used for targeting in the different districts. Watkins (2008) recognizes this and argues for greater harmonization in future.
} 
will decrease the variance of an estimated treatment effect without increasing bias. They also demonstrate that including variables that are related to the treatment but not to the outcome will increase the variance of the estimated treatment effect without decreasing bias.Thus, following Brookhart et al. (2006), we include in $\mathbf{x}$ all covariates that are significantly correlated with the outcome variable, whether or not they are correlated with the treatment variable. We, however, exclude all covariates that are themselves affected by the treatment, such as income and asset endowment (Maertens and Swinnen 2009; Brookhart et al. 2006).

Impact was estimated using propensity score matching (PSM) and Hirano, Imbens \& Ridder's (2003) propensity score weighting (PSW), or odds-weighted regression, approach. PSM involves finding, for each treatment unit, matches in the control group based on observable characteristics (Abadie \& Imbens, 2005; Dehejia \& Wahba, 2002). Thus, the ATT was computed as the weighted average of the difference in the outcome variable between treatment households and matched control ones. We match using kernel functions and perform inferences using bootstrapped standard errors. ${ }^{13}$ The kernel matching estimator is given as (Heckman, Ichimura, \& Todd 1997; Smith \& Todd, 2005; Gilligan \& Hoddinott, 2007)

$$
A T T=\frac{1}{n} \sum_{i \in T}\left\{Y_{1 i}-\frac{\sum_{j \in C} Y_{0 j} K\left(\frac{P_{j}(\mathbf{x})-P_{i}(\mathbf{x})}{a_{n}}\right)}{\sum_{k \in C} K\left(\frac{P_{k}(\mathbf{x})-P_{i}(\mathbf{x})}{a_{n}}\right)}\right\},
$$

where $T$ is the treatment group participants, $C$ refers to the comparison group, $K$ is the kernel function, and $a_{n}$ is the kernel bandwidth.

Unlike PSM, which is consistent, PSW has been shown to produce fully efficient estimates (Hirano, Imbens and Ridder 2003). Under the PSW framework, impact is the estimated slope coefficient $\hat{\beta}_{1}$ in the weighted-regression model

$$
\ln (y)=\beta_{0}+\beta_{1} w+e,
$$

where the observations are weighted by 1 for treatment households and by the odds ratio, $\hat{P}(\mathbf{x}) /(1-\hat{P}(\mathbf{x}))$, for comparison households; $\hat{P}(\mathbf{x})=E(w=1 \mid \mathbf{x})$ is the conditional probability of participation estimated in (2); $\beta_{0}$ and $\beta_{1}$ are parameters to be estimated; and $e$ is a zero-mean error term. The dependent variable, $\ln (y)$, is the natural $\operatorname{logarithm}$ of per capita consumption expenditure on food, non-food or both.

\subsubsection{Heterogeneous Impact}

One of the advantages of the weighted-regression approach to PSM is that it can be readily extended to measure differential impacts across some defined sub-groups of the population. In our case, two groups were formed based on an asset-wealth index constructed using principal components analysis (Filmer \& Pritchett, 2001). Disaggregating impact by asset wealth helped to test whether the SCTs benefitted the poorer of the ultra poor the most. Based on this index, households were grouped into two categories (see Figure A1): i) the asset poor households (i.e. the 60 percent with an asset wealth index of zero or less), and ii) the relatively less asset poor (i.e. those with wealth index above zero). Thus, heterogeneous impact was estimated as

$$
\ln (y)=\gamma_{0}+\gamma_{1} w+\gamma_{2} w^{*} D+u,
$$

where $D$ is a dummy variable equal to 1 if the household was categorized as asset poor and zero otherwise; $\gamma_{0}, \gamma_{1}$, and $\gamma_{2}$ are parameters to be estimated; and $u$ is a zero-mean error term. As in Equation (3), the observations are weighted by 1 for treatment households and by $\hat{P}(\mathbf{x}) /(1-\hat{P}(\mathbf{x}))$ for comparison households. Based on (4), the impact of the programme on the outcome variable is equal to $\hat{\gamma}_{1}$ for the relatively less poor households $(D=0)$ and $\hat{\gamma}_{1}+\hat{\gamma}_{2}$ for the poorer ones $(D=1)$. Thus, $\hat{\gamma}_{2}$ is the additional impact that a poor household would experience relative to its less poor counterparts.

\subsubsection{Balancing Tests and Common Support}

The propensity score is only as good as the quality of the matching, and any propensity-score-based estimator would be unbiased only under certain identifying assumptions. The balancing effects of the propensity score were tested using a number of procedures, including $t$ tests for the differences in covariate means between the two groups (participants and non-participants) before and after the matching (Rosenbaum and Rubin 1985), effectiveness in reducing standardized bias to within acceptable levels (no more than 5 percent), and ability to drive the overall probit relationship to

${ }^{13}$ Kernel matching, unlike nearest-neighbor matching, arguably leads to more valid bootstrapped standard errors (Abadie \& Imbens, 2005; Gilligan \& Hodinott, 2007). 
insignificance as measured by a joint likelihood ratio (LR) test and pseudo $R^{2}$ (Caliendo \& Kopeinig, 2008 ). ${ }^{14}$ The results show that all these balancing requirements were satisfied using our specification of the propensity score model (see Table A1). ${ }^{15}$ The estimated propensity scores also satisfied the common support requirement, with the region of common support being within $(0.113,0.968)$ of the propensity score distribution (see Figure A2).

\section{Results}

\subsection{Descriptive Statistics}

The descriptive results confirm that the SCT target population is extremely poor, characterized by elderly (59 years old on average) and lowly educated heads (2.7 years), high dependency ratios ( 8.6 effectively inactive members for every active member), and high incidences of female- and widow-headed households (Table 2).

Table 2. Characteristics of the SCT target population in Kalomo District

\begin{tabular}{|c|c|c|c|c|}
\hline \multirow[b]{2}{*}{ Variable label } & \multirow[b]{2}{*}{ Full sample } & \multicolumn{3}{|c|}{ Sub-samples } \\
\hline & & Control & Treatment & \\
\hline Male-headed households (\%) & 36.0 & 41.0 & 31.0 & $* * *$ \\
\hline Age of household head (years) & 58.91 & 55.08 & 63.47 & $* * *$ \\
\hline Education level of household head (years) & 2.67 & 3.30 & 1.92 & $* * *$ \\
\hline Widow-headed households $(\%)$ & 63.0 & 56.0 & 71.0 & $* * *$ \\
\hline Effective dependency ratio & 8.60 & 6.73 & 10.83 & $* * *$ \\
\hline Number of children 14 years or younger & 2.03 & 2.13 & 1.91 & $*$ \\
\hline Number of male members $15-30$ years & 0.55 & 0.58 & 0.51 & \\
\hline Number of female members $15-30$ years & 0.50 & 0.55 & 0.43 & $* *$ \\
\hline Number of male members $31-45$ years & 0.10 & 0.12 & 0.08 & $*$ \\
\hline Number of female members $31-45$ years & 0.18 & 0.22 & 0.15 & $* *$ \\
\hline Number of male members $46-60$ years & 0.11 & 0.14 & 0.07 & $* * *$ \\
\hline Number of female members $46-60$ years & 0.29 & 0.34 & 0.23 & $* * *$ \\
\hline Number of members 61 years and above & 0.69 & 0.54 & 0.85 & $* * *$ \\
\hline Orphaned children 16 years or younger $(\%)$ & 47.0 & 43.0 & 53.0 & $* * *$ \\
\hline Value of main house (million ZMK) & 0.20 & 0.24 & 0.15 & $*$ \\
\hline Asset wealth index ${ }^{1}$ & 0.00 & 0.04 & -0.05 & \\
\hline Landholding size (ha) & 2.38 & 2.71 & 1.99 & $* *$ \\
\hline Cropped land area in $2006 / 07$ (ha) & 1.46 & 2.00 & 0.81 & $* *$ \\
\hline Per capita income ('000 ZMK) & 115.78 & 141.40 & 85.29 & $* * *$ \\
\hline Per capita expenditure ('000 ZMK) & 138.59 & 126.50 & 152.98 & $* * *$ \\
\hline Distance to nearest main road $(\mathrm{km})$ & 1.13 & 1.27 & 0.96 & \\
\hline Distance to nearest secondary school (km) & 26.13 & 24.47 & 28.12 & $* *$ \\
\hline Distance to nearest under-five post (km) & 4.21 & 4.60 & 3.75 & $*$ \\
\hline
\end{tabular}

${ }^{1} \mathrm{~A}$ unitless index computed from asset endowment using principal components analysis (PCA)

About 47 percent of children under 16 years were orphaned. An average household owns 2.4 hectares of land, of which 1.5 (or 61 percent) is cultivated and planted to crops. Income levels are generally very low, averaging about 115,780 Zambian Kwacha (or USD 31.30) per capita.

Compared to the control group, treatment households are significantly more likely to be female- and elderly-headed,

14 A well-balanced propensity score is necessary for artificially constructing an experimental environment from a quasi-experimental situation. The idea is that there should be no association between treatment status and each covariate once the observations have been restricted to the region of common support. Estimation of the propensity score and generation of balancing tests were achieved by using psmatch2 (Leuven and Sianesi 2003), pscore (Becker \& Ichino, 2002) and pstest (Leuven \& Sianesi, 2003) procedures in Stata (StataCorp, 2003).

15 A key identifying assumption for the PSM is that there should be no unobserved factors (not explicitly accounted for in Equation 2) that influence both participation and the outcome variable. This is variantly known in the literature as the conditional independence assumption (CIA), matching on observables, unconfoundedness, etc. More generally, PSM is prone to what has come to be known as 'hidden bias' if there are unobserved factors that influence both participation and the outcome variable (Rosenbaum \& Rubin, 1983; Caliendo \& Kopeinig, 2008; Jalan \& Ravallion, 2003). Hidden bias arises from two sources, omitted variables and/or unobserved and unknown factors (Cameron \& Trivedi, 2005). The standard procedure of using interaction terms and higher order polynomials in the specification of the propensity score (as explained above) helps to deal with the former. The latter, on the other hand, is non-testable but is not an issue if we assume that the unobserved factors are equally distributed between the two groups. 
and to host orphaned children and elderly members. They also have significantly lower per capita income, landholding sizes, and cultivated land area.

Table 3. Probit results for the household participation model in Kalomo

\begin{tabular}{|c|c|c|c|}
\hline Variable & Variable description & Parameter estimate & Marginal effect \\
\hline & & $(1)$ & $(2)$ \\
\hline \multirow{2}{*}{\multicolumn{2}{|c|}{ Constant }} & -0.216 & \\
\hline & & $(0.46)$ & \\
\hline \multirow[t]{2}{*}{ hage } & Age of the household head (years) & $-0.0391 * * *$ & -0.0155 \\
\hline & & $(0.014)$ & \\
\hline \multirow[t]{2}{*}{ hag2 } & Age of head squared & $0.0006 * * *$ & 0.0002 \\
\hline & & $(0.00013)$ & \\
\hline \multirow[t]{2}{*}{ dmar } & Marital status of head, $1=$ married & -0.143 & -0.0563 \\
\hline & & $(0.17)$ & \\
\hline \multirow[t]{2}{*}{ dwido } & Marital status of head, $1=$ widowed & 0.207 & 0.0817 \\
\hline & & $(0.24)$ & \\
\hline \multirow[t]{2}{*}{ maxedu } & Education of most educated member (years) & 0.0124 & 0.0049 \\
\hline & & $(0.028)$ & \\
\hline \multirow[t]{2}{*}{ edwid } & maxedu $\mathrm{x}$ dwido interaction & -0.0136 & -0.0054 \\
\hline & & $(0.031)$ & \\
\hline \multirow[t]{2}{*}{$\mathrm{m} 15$ to 30} & Male members $15-30$ years old & -0.0297 & -0.0118 \\
\hline & & $(0.058)$ & \\
\hline \multirow[t]{2}{*}{ f15to30 } & Female members $15-30$ years old & -0.0643 & -0.0255 \\
\hline & & $(0.064)$ & \\
\hline \multirow[t]{2}{*}{ f31 to 45} & Female members $31-45$ years old & 0.0678 & 0.0268 \\
\hline & & $(0.11)$ & \\
\hline \multirow[t]{2}{*}{ dove } & Orphaned children dummy, $1=$ yes & $0.1950 * *$ & 0.0771 \\
\hline & & $(0.096)$ & \\
\hline \multirow[t]{2}{*}{ tland } & Landholding size (ha) & -0.0164 & -0.00650 \\
\hline & & $(0.013)$ & \\
\hline \multirow[t]{2}{*}{ kmroad } & Distance to nearest main road $(\mathrm{km})$ & -0.0116 & -0.0046 \\
\hline & & $(0.020)$ & \\
\hline \multirow[t]{2}{*}{ kmsec } & Distance to secondary school (km) & $0.0076 * * *$ & 0.003 \\
\hline & & $(0.0026)$ & \\
\hline \multirow[t]{2}{*}{ kmhosp } & Distance to nearest hospital $(\mathrm{km})$ & -0.0013 & -0.0005 \\
\hline & & $(0.0058)$ & \\
\hline \multirow[t]{2}{*}{ kmu5 } & Distance to nearest under-five post (km) & -0.0079 & -0.0031 \\
\hline & & $(0.0078)$ & \\
\hline \multicolumn{2}{|c|}{ Joint significance of location dummies } & $12.58 * *$ & \\
\hline \multicolumn{2}{|c|}{ Goodness-of-fit Chi-square } & $133.78 * * *$ & \\
\hline \multicolumn{2}{|c|}{ Log likelihood } & -530.82 & \\
\hline \multicolumn{2}{|c|}{ Cragg \& Uhler's $R^{2}$} & 0.191 & \\
\hline \multicolumn{2}{|c|}{ Observed probability of participation } & 0.457 & \\
\hline \multicolumn{2}{|c|}{ Predicted probability of participation } & 0.451 & \\
\hline \multicolumn{2}{|c|}{ Number of observations } & 867 & \\
\hline
\end{tabular}

Level of significance: $*=10$ percent, $* *=5$ percent, $* * *=1$ percent

Source: Data from Kalomo household survey, 2007

\subsection{Propensity Score Model Results}

Table 3 presents the parameter estimates and marginal effects from a probit model of participation for eligible households. Overall, the model was a very good and significant fit $\left(\chi^{2}=133.78 ; p\right.$-value $\left.<0.001\right)$. The results also indicate interesting systematic differences between participating households and their non-participating but eligible counterparts. The probability of participation in the SCT scheme was directly and significantly correlated with hosting of orphaned children, the age of the household head and distance to the nearest secondary school. In much of rural Zambia, secondary schools are located in or close to district urban area.

That participants were more likely to be further from towns and to host orphans is consistent with a priori expectations. Households that hosted orphans were 7.7 percent more likely to be in the scheme than those that did not whereas an additional kilometre away from town raised the probability of participation by 0.3 percent. The specific geographical location of the household also mattered as indicated by significant joint test of location dummy variables. 
The age of the households head was also a significant determinant of participation at 1 percent level. Age also exhibits an expected U-shaped relationship with the probability of participation. That is, the probability of being a beneficiary declines at a decreasing rate as the age of the household head increases. This is consistent with expectations and targeting criteria as it implies that child-headed and elderly-headed households are more likely to be in the scheme than their counterparts that are headed by prime-age adults.

It should be noted that these results do not constitute an assessment of targeting effectiveness. As earlier stated, our sample was drawn from the programme participants (i.e. the 10 percent most incapacitated of the ultra poor) as well as from those that had qualified to be in the programme but were left out only because of the 10 percent ceiling. Thus, the probit model represents only the selection process from among the eligible group. ${ }^{16}$

Table 4. Propensity score matching and odds-weighted regression estimates of the impact of the Kalomo SCT pilot scheme on per capita consumption expenditure

\begin{tabular}{|c|c|c|c|c|}
\hline \multirow[b]{2}{*}{ Variable } & \multirow[b]{2}{*}{ Variable description } & \multirow{2}{*}{$\begin{array}{l}\text { Propensity score } \\
\text { matching }\end{array}$} & \multicolumn{2}{|c|}{ Odds-weighted regression } \\
\hline & & & Overall & Heterogeneous \\
\hline & & (1) & (2) & $(3)$ \\
\hline Constant & & - & $\begin{array}{c}11.28 * * * \\
(0.070)\end{array}$ & $\begin{array}{l}11.278 * * * \\
(0.096)\end{array}$ \\
\hline$w$ & $\begin{array}{l}\text { Treatment indicator, } \\
1=\text { participant }\end{array}$ & $\begin{array}{c}0.270 * * * \\
(0.085)\end{array}$ & $\begin{array}{c}0.314 * * * \\
(0.085)\end{array}$ & $\begin{array}{c}0.334 * * * \\
(0.090)\end{array}$ \\
\hline$w \times D$ & $\begin{array}{l}w \text { interacted with wealth dummy } \\
(D, 1=\text { poor })\end{array}$ & - & - & $\begin{array}{l}-0.034 \\
(0.093)\end{array}$ \\
\hline Goodness & fit $(\mathrm{F}$ statistic) & - & $13.65 * * *$ & $7.61 * *$ \\
\hline Number 0 & bservations & 845 & 845 & 845 \\
\hline
\end{tabular}

Level of significance: $*=10$ percent, $* *=5$ percent, $* * *=1$ percent

Dependent variable: Natural logs of per capita consumption expenditure

Source: Data from Kalomo household survey, 2007

\subsection{Impact on Consumption Expenditure}

Table 4 presents propensity score matching (Column 1) and odds-weighted regression (Columns $2 \& 3$ ) estimates of the impact of social cash transfers on per capita consumption expenditure. While columns 1 and 2 assume a common mean impact, column 3 tests the assertion that the impact will differ by the household's wealth status. Overall, the impact of the SCT scheme on consumption expenditure was unambiguously positive and statistically significant, accounting for 27-33 percent of the beneficiary households' per capita consumption expenditure (Table 4). The impact was especially large for relatively wealthier households although the difference was not statistically significant (Column 3).

Table 5. Propensity score matching and odds-weighted regression estimates of the impact of the Kalomo SCT pilot scheme on per capita food consumption expenditure

\begin{tabular}{|c|c|c|c|c|}
\hline \multirow[b]{2}{*}{ Variable } & \multirow[b]{2}{*}{ Variable description } & \multirow{2}{*}{$\begin{array}{l}\text { Propensity score } \\
\text { matching }\end{array}$} & \multicolumn{2}{|c|}{ Odds-weighted regression } \\
\hline & & & Overall & Heterogeneous \\
\hline \multirow{3}{*}{ Constant } & & (1) & (2) & (3) \\
\hline & & - & $10.872 * * *$ & $10.872 * * *$ \\
\hline & & & $(0.081)$ & $(0.081)$ \\
\hline \multirow[t]{2}{*}{$w$} & Treatment & $0.205^{* * *}$ & $0.256^{* *}$ & $0.203^{*}$ \\
\hline & 1=participant & $(0.085)$ & $(0.100)$ & $(0.105)$ \\
\hline$w \times D$ & $\begin{array}{l}w \text { interacted with wealth } \\
\text { dummy }(D, 1=\text { poor })\end{array}$ & - & - & $\begin{array}{c}0.088 \\
(0.112) \\
\end{array}$ \\
\hline \multicolumn{2}{|c|}{ Goodness of fit (F statistic) } & - & $6.49 * * *$ & $3.25 * *$ \\
\hline \multicolumn{2}{|c|}{ Number of observations } & 845 & 845 & 845 \\
\hline
\end{tabular}

Level of significance: $*=10$ percent, $* *=5$ percent, $* * *=1$ percent

Dependent variable: Natural logs of per capita consumption expenditure

Source: Data from Kalomo household survey, 2007

${ }^{16}$ The correct comparison group for a targeting evaluation is all households other than the participants. 
The general results do not change much when analysis is confined to per capita expenditure on food-related items only (Table 5). However, the magnitudes of the impact are slightly lower at 20-26 percent though still statistically significant. Another distinct difference is that, for food expenditure poor households seem to gain 8.8 percent more from participation than their wealthier counterparts though, as before, the difference is not statistically significant.

Table 6. Propensity score matching and odds-weighted regression estimates of the impact of the Kalomo SCT pilot scheme on per capita non-food consumption expenditure

\begin{tabular}{|c|c|c|c|c|}
\hline \multirow[b]{2}{*}{ Variable } & \multirow[b]{2}{*}{ Variable description } & \multirow{2}{*}{$\begin{array}{c}\text { Propensity score } \\
\text { matching }\end{array}$} & \multicolumn{2}{|c|}{ Odds-weighted regression } \\
\hline & & & Overall & Heterogeneous \\
\hline & & (1) & (2) & $(3)$ \\
\hline Constant & & - & $\begin{array}{c}8.896 * * * \\
(0.194)\end{array}$ & $\begin{array}{c}8.896 * * * \\
(0.194)\end{array}$ \\
\hline$w$ & $\begin{array}{l}\text { Treatment indicator, } \\
1=\text { participant }\end{array}$ & $\begin{array}{c}0.758 * * * \\
(0.246)\end{array}$ & $\begin{array}{c}0.733 * * * \\
(0.239)\end{array}$ & $\begin{array}{l}1.299 * * * \\
(0.251)\end{array}$ \\
\hline$w \times D$ & $\begin{array}{l}w \text { interacted with wealth } \\
\text { dummy }(D, 1=\text { poor })\end{array}$ & - & - & $\begin{array}{c}-0.962 * * * \\
(0.260)\end{array}$ \\
\hline \multirow{2}{*}{\multicolumn{2}{|c|}{$\begin{array}{l}\text { Goodness of fit (F statistic) } \\
\text { Number of observations }\end{array}$}} & - & 9.37 *** & $15.15^{* * *}$ \\
\hline & & 845 & 845 & 845 \\
\hline
\end{tabular}

Level of significance: $*=10$ percent, $* *=5$ percent, $* * *=1$ percent

Dependent variable: Natural logs of per capita consumption expenditure

Source: Data from Kalomo household survey, 2007

Table 6 presents PSM and OWR impact estimates on consumption expenditure on non-food items. The results seem to suggest that SCTs are especially effective in raising non-food consumption expenditure, contributing 73-76 percent to beneficiary households' per capita non-food consumption expenditure. When disaggregated by asset wealth, the impact of participation on per capita non-food expenditure was significantly larger among non-poor households (130 percent) compared to their poorer counterparts (34 percent).

\section{Summary and Conclusions}

This paper reports the impact of the Kalomo social cash transfer scheme, Zambia's oldest SCT scheme, on consumption expenditure. Impact results suggest that the scheme is achieving its primary objective of improving immediate welfare, as indicated by its consistently positive impact on per capita consumption expenditure. That the impact on non-food expenditure is greater among non-poor households suggests that these households use a substantial portion of their cash transfers to further re-enforce their asset base. It also signifies the presence of possible threshold effects, where a minimum level of asset base is required for a beneficiary household to be able to use a substantial portion of the transfer on asset accumulation. This assertion is further reinforced by the finding that poorer households experience greater impact on per capita food consumption expenditure. These variations of the nature and distribution of impacts across wealth levels identify the need for impact studies to not only measure aggregate impact but also to measure heterogeneous effects of the interventions. .

\section{Acknowledgements}

This paper is based on earlier work done by the authors on behalf of and with support from the World Bank, the UK Department for International Development (DfID), the German Technical Cooperation (GIZ), the United Nations Children Fund (UNICEF), and CARE International. The authors would also like to acknowledge the valuable comments received from one anonymous reviewer. Elizabeth Chishimba and Brian P. Mulenga provided invaluable research assistance during the preparation of this manuscript. However, the views expressed herein do not necessarily represent the position of any of these organizations and individuals. All errors in interpretation are the authors' own.

\section{References}

Aguëro, J.M., Carter, M.R., \& Woodlard, I. (2006). The impact of unconditional cash transfers on nutrition: The South African Child Support Grant. Southern Africa Labour and Development Research Unit Working Paper Number 06/08. Cape Town:SALDRU, University of Cape Town.

Angelucci, M., \& Giorgi, G. D. (2009). Indirect Effects of an Aid Program: How Do Cash Injections Affect Ineligibles' $\begin{array}{lllll}\text { Consumption. } & \text { American } & \text { Economic } & \text { Review, } & \text { 99, }\end{array}$ http://www.aeaweb.org/articles.php?doi=10.1257/aer.99.1.486 
Barker, J.L. (2000). Evaluating the Impact of Development Projects on Poverty. Washington DC: The World Bank.

Barrientos, A., \& Dejong, J. (2006). Reducing child poverty with cash transfers: A sure thing? Development Policy Review, 24, 537-552. http:dx.doi.org/10.1111/j.1467-7679.2006.00346.x

Becker, S. O., \& Ichino, A.. (2002). Estimation of Average Treatment Effects based on Propensity Scores. Stata Journal, 2, 358-77. http://www.stata-journal.com/sjpdf.html?articlenum=st0026.

Brookhart, M.A., Schneeweiss, S., Rothman, K.J., Glynn, R.J., Avorn, J., \& Sturmer, T. 2006. Variable Selection for Propensity Score Models. American Journal of Epidemiology, 163, 1149-1156. http://pubmedcentralcanada.ca/pmcc/articles/PMC1513192/

Caliendo, M., \& Kopeinig, S. (2008). Some Practical Guidance for the Implementation of Propensity Score Matching. Journal of Economic Surveys, 22, 31-72. http:dx.doi.org/10.1111/j.1467-6419.2007.00527.x

Cameron, C.A., \& Trivedi, P.K. (2005). Microeconometrics: Methods and Applications. Cambridge: Cambridge University Press.

CARE International Zambia. (2008). Presentation on Capacity Building of Department of Social Welfare in Relation to Targeting: The Case of Chipata and Katete Social Cash Transfers Schemes. Lusaka, Zambia: CARE International.

Carraro, R., \& Marzi, M. (2013). Assessment of Targeting Mechanisms of the Zambia Social Protection Expansion Programme. Oxford Policy Management. http://www.opml.co.uk/projects/assessment-targeting-mechanisms-zambia-social-protection-expansion-programme

Case, A., \& Deaton, A. (1998). Large cash transfers to the Elderly in South Africa. The Economic Journal, 108, 1330-1361. http:dx.doi.org/10.1111/1468-0297.00345

Commission for Africa. (2005). Our Common Interest: Report of the Commission for Africa. London, UK: Council of Foreign Relations. http://www.cfr.org/publication.html?id=8292.

CSO (Central Statistical Office). (2006). 2006 Living Conditions Monitoring Survey. Lusaka, Zambia: Central Statistical Office.

Daidone, S., Davis, B., Dewbre, J., Gonzalez-Flores, M., Handa, S., Seidenfeld, D., \& Tembo, G. (2013). Out-of-Silo Effects of Social Cash Transfers: The Impact on Livelihoods and Economic Activities of the Child Grand Programme in Zambia. Paper submitted for presentation at the Oxford CSAE conference, Oxford, UK.

Duflo, E. (2000). Grandmothers and Granddaughters: Old Age Pension and intra-household allocation in South Africa. The World Bank Economic Review, 17(1), 1-25. http:dx.doi.org/10.1093/wber/ihg013.

Filmer, D., \& Pritchett, L.H. (2001). Estimating Wealth Effects without Expenditure Data or Tears: An Application to Educational Enrollments of India. Demography, 38(1), 115-132 .http:dx.doi.org/10.1353/dem.2001.0003

Garcia, M., \& Moore, C.M.T. (2012). The Cash Dividend: The Rise of Cash Transfer Programs in Sub-Saharan Africa. The World Bank, Directions in Development, Human Development, Washington DC, USA.

Gertler, P., Martinez, S., \& Rubio-Codina, M. (2006). Investing Cash Transfers to Raise Long-Term Living Standards. Policy Research Working Paper 3994, Impact Evaluation Series Number 6, The World Bank, Washington DC. http://ssrn.com/abstract=926443

Hamoonga, J. (2007). Personal communication. Kalomo, Zambia.

Handa, S., Peterman, A., Seidenfeld, D., \& Tembo, G. (2013a). Income shocks and maternal health: Evidence from a national randomized social cash transfer program in Zambia. Unpublished.

Handa, S., Seidenfeld, D., \& Tembo, G. (2012). The Impact of a Large Scale Poverty Targeted Cash Transfer Program on Time Preference. Unpublished.

Handa, S., Seidenfeld, D., Tembo, G., Prencipe, L., \& Peterman, A. (2013b). Zambia's Child Grant Program: 24-Month Impact Report. Washington DC, USA: American Institutes for Research (AIR).

Hirano, K., Imbens, G.W., \& Ridder, G. (2003). Efficient Estimation of Average Treatment Effects using the Estimated Propensity Score. Research Paper Number C02-13, USC Center for Law, Economics and Organization, University of Southern California Law School, Los Angeles, California, USA.

Jalan, J., \& Ravallion, M. (2003). Estimating the Benefit Incidence of an Antipoverty Program by Propensity Score Matching. Journal of Business and Economic Statistics, 21, 19-30. http:dx.doi.org/10.1198/073500102288618720

Leuven, E., \& Sianesi, B. (2003). PSMATCH2: Stata Module to Perform full Mahalanobis and Propensity Score Matching, Common Support Graphing, and Covariate Imbalance Testing. http://ideas.repec.org/c/boc/bocode/s432001.html. 
MCDSS \& GTZ SSN. (2007a). Manual of Operations, Pilot Social Cash Transfer Scheme, $7^{\text {th }}$ Edition. Lusaka, Zambia: Ministry of Community Development, Mother and Child Health..

MCDSS \& GTZ SSN. (2007b). The Pilot Social Cash Transfer Scheme in Zambia Summary Report. Lusaka, Zambia: Ministry of Community Development, Mother and Child Health.

Miller, C.M., Tsoka, M., \& Reichert, K. (2011). The impact of the Social Cash Transfer Scheme on food security in Malawi. Food Policy, 36, 230-238. http://dx.doi.org/10.1016/j.foodpol.2010.11.020.

Ravallion, M. (2003). Assessing the Poverty Impact of an Assigned Program. In WB (Eds). (2003). The Toolkit for Evaluating the Poverty and Distributional Impact of Economic Policies, Washington DC: The World Bank, EDI Development Studies.

Ravallion, M. (2001). The Mystery of the Vanishing Benefits: An Introduction to Impact Evaluation. The World Bank Economic Review, 15, 115-140. http:dx.doi.org/10.1093/wber/15.1.115

RHVP (Regional Hunger and Vulnerability Programme). (2007). Social Cash Transfers, Zambia. Regional Evidence Building Agenda (REBA) Case Study Brief Number 2, RHVP, Johannesburg, RSA. www.wahenga.net.

Rosenbaum, P., \& Rubin, D. (1983). The Central Role of the Propensity Score in Observational Studies for Causal Effects. Biometrika, 70, 41-55. http://dx.doi.org/10.1093/biomet/70.1.41.

Rosenbaum, P., \& Rubin, D. (1985). Constructing a Control Group using Multivariate Matched Sampling Methods that Incorporate the Propensity Score. American Statistician, 39, 33-38. http://dx.doi.org/10.1080/00031305.1985.10479383

Sadoulet, E., de Janvry, A., \& Davis, B. (2001). Cash Transfer Programs with Income Multipliers: PROCAMPO in Mexico. World Development, 29, 1043-1056. http://dx.doi.org/10.1016/s0305-750x(01)00018-3.

Schubert, B., \& Slater, R. (2006). Social Cash Transfers in Low-Income African Countries: Conditional or Unconditional? Development Policy Review, 24, 571-578.

Schüring, E., Michelo, S., \& Boonstoppel, E. (2007). Final Evaluation Report: Kalomo Cash Transfer Scheme. Lusaka, Zambia: MCDSS/GTZ.

Seidenfeld, D., Handa, S., Prencipe, L., Huang, C., Tembo, G., \& Sherman, D. (2011). Results of the Three Year Impact Evaluation of Zambia's Cash Transfer Program in Monze District. Washington DC, USA: American Institutes for Research.

Standing, G. (2008). How cash transfers promote the case for basic income. Basic Income Studies, 3(1), 1-30. http://dx.doi.org/10.2202/1944-2858.1078.

StataCorp. (2008). Stata Statistical Software: Release 10. College Station, TX: StataCorp LP.

Tabor, S.R. (2002). Assisting the Poor with Cash: Design and Implementation of Social Transfer Programs. Social Protection Discussion Paper Series, Number 0223, Social Protection Unit, Human Development Network, The World Bank, Washington DC.

Tembo, G. \& Freeland, N. (2008a). Baseline Survey Report for the Monze Social Cash Transfer Programme. Lusaka, Zambia: Palm Associates Limited/Masdar International Consultants.

Tembo, G., \& Freeland, N. (2008b). Impact of Social Cash Transfers on Household Welfare, Investment and Education. Lusaka, Zambia: Palm Associates Limited/Masdar International Consultants..

Watkins, B. (2008). Independent Monitoring and Evaluation Study: Alternative Methods for Targeting Social Assistance to Highly Vulnerable Groups. Nairobi, Kenya: Kimetrika.

Wietler, K. (2007). The Impact of Social Cash Transfers on Informal Safety Nets in Kalomo District Zambia. Lusaka, Zambia: MCDSS/GTZ

Wooldridge, J.M. (2002). Econometric Analysis of Cross Section and Panel Data. Massachusetts: The MIT Press.

Wooldridge, J.M. (2006). Introductory Econometrics: A Modern Approach $3^{\text {rd }}$ Edition, Mason, Ohio: Thomson South-Western. 


\section{Appendix}

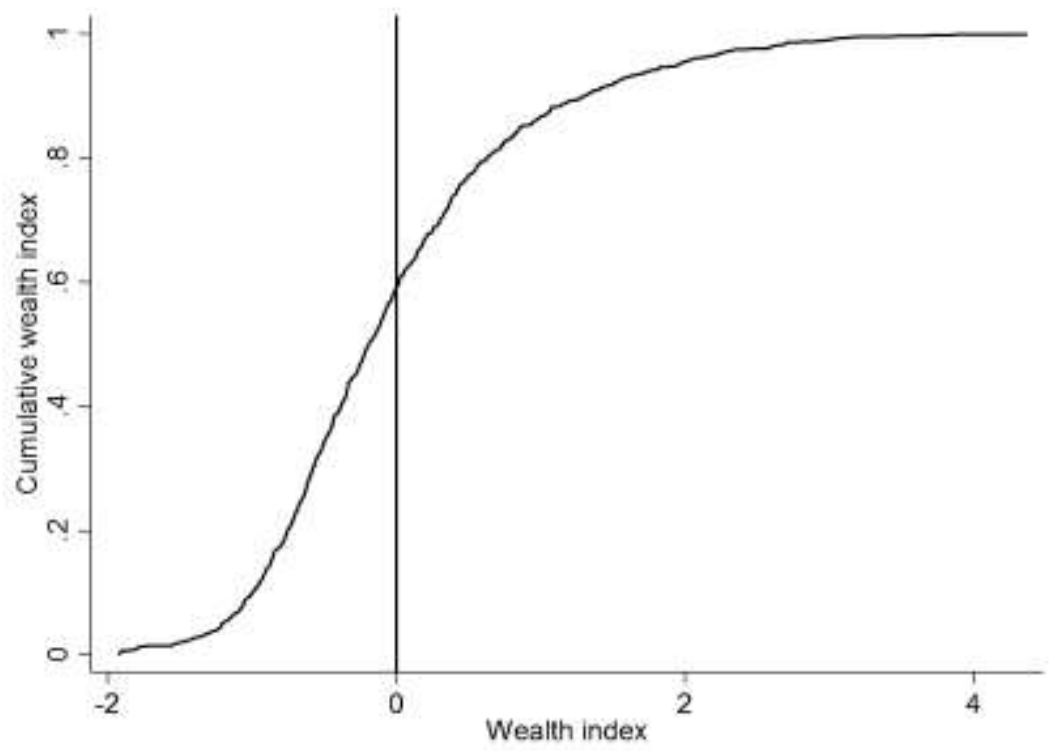

Figure A1. Distribution of asset wealth index

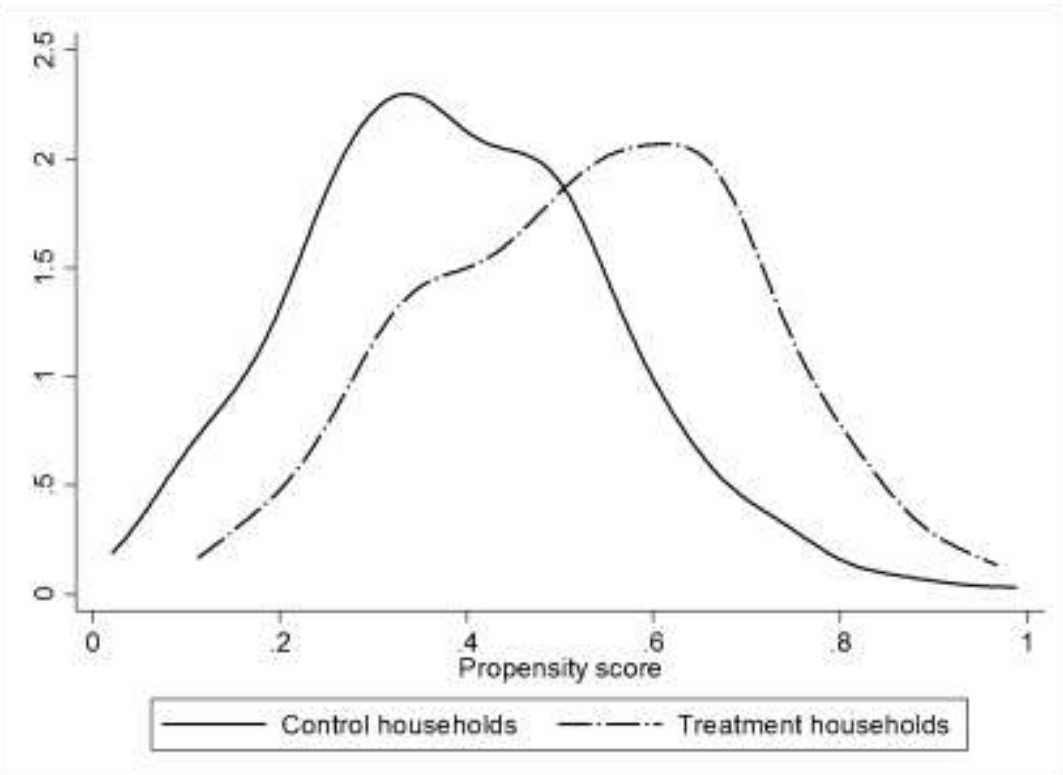

Figure A2. Region of common support: Kernel density functions for control and treatment households 
Table A1. Balancing properties of covariates in treated and control groups in Kalomo

\begin{tabular}{|c|c|c|c|c|c|c|c|}
\hline \multirow[b]{2}{*}{ Variable } & \multirow[b]{2}{*}{ Sample } & \multirow{2}{*}{$\begin{array}{c}\text { Mean } \\
\text { treated } \\
\text { units }\end{array}$} & \multirow{2}{*}{$\begin{array}{c}\text { Mean } \\
\text { control } \\
\text { units }\end{array}$} & \multirow{2}{*}{$\begin{array}{c}\% \text { bias between } \\
\text { treated and } \\
\text { controls }\end{array}$} & \multirow{2}{*}{$\begin{array}{c}\% \\
\text { reduction } \\
\text { in |bias }\end{array}$} & \multicolumn{2}{|c|}{$\begin{array}{c}\mathrm{H}_{0}: \text { mean }(\text { treated })= \\
\text { mean }(\text { control })\end{array}$} \\
\hline & & & & & & $t$ & Prob $>|t|$ \\
\hline & & (1) & (2) & (3) & (4) & (5) & (6) \\
\hline \multirow[t]{2}{*}{ hage } & Unmatched & 63.474 & 55.077 & 57.7 & & 8.48 & 0.000 \\
\hline & Matched & 63.474 & 62.309 & 8.0 & 86.1 & 1.12 & 0.263 \\
\hline \multirow[t]{2}{*}{ hag2 } & Unmatched & $4,243.6$ & $3,240.8$ & 62.6 & & 9.23 & 0.000 \\
\hline & Matched & $4,243.6$ & $4,094.8$ & 9.3 & 85.2 & 1.26 & 0.208 \\
\hline \multirow[t]{2}{*}{ dmar } & Unmatched & 0.210 & 0.323 & -25.8 & & -3.76 & 0.000 \\
\hline & Matched & 0.210 & 0.202 & 1.7 & 93.5 & 0.25 & 0.799 \\
\hline \multirow[t]{2}{*}{ dwido } & Unmatched & 0.712 & 0.552 & 33.6 & & 4.91 & 0.000 \\
\hline & Matched & 0.712 & 0.716 & -0.8 & 97.5 & -0.12 & 0.903 \\
\hline \multirow[t]{2}{*}{ maxedu } & Unmatched & 6.116 & 6.452 & -10.3 & & -1.51 & 0.131 \\
\hline & Matched & 6.116 & 6.026 & 2.8 & 73.1 & 0.37 & 0.708 \\
\hline \multirow[t]{2}{*}{ edwid } & Unmatched & 4.220 & 3.403 & 20.6 & & 3.02 & 0.003 \\
\hline & Matched & 4.220 & 4.123 & 2.4 & 88.2 & 0.34 & 0.732 \\
\hline \multirow[t]{2}{*}{ m15to30 } & Unmatched & 0.513 & 0.582 & -8.0 & & -1.16 & 0.245 \\
\hline & Matched & 0.513 & 0.496 & 1.9 & 75.8 & 0.27 & 0.785 \\
\hline \multirow[t]{2}{*}{ f15to30 } & Unmatched & 0.439 & 0.565 & -16.3 & & -2.38 & 0.018 \\
\hline & Matched & 0.439 & 0.439 & 0.0 & 99.7 & 0.01 & 0.994 \\
\hline \multirow[t]{2}{*}{ f31to45 } & Unmatched & 0.146 & 0.221 & -17.7 & & -2.60 & 0.010 \\
\hline & Matched & 0.146 & 0.162 & -3.6 & 79.6 & -0.54 & 0.589 \\
\hline \multirow[t]{2}{*}{ tland } & Unmatched & 2.000 & 2.721 & -15.6 & & -2.23 & 0.026 \\
\hline & Matched & 2.000 & 2.032 & -0.7 & 95.6 & -0.17 & 0.862 \\
\hline \multirow[t]{2}{*}{ kmroad } & Unmatched & 0.953 & 1.274 & -11.1 & & -1.60 & 0.110 \\
\hline & Matched & 0.953 & 0.902 & 1.8 & 84.0 & 0.33 & 0.742 \\
\hline \multirow[t]{2}{*}{ kmsec } & Unmatched & 28.371 & 24.460 & 17.7 & & 2.62 & 0.009 \\
\hline & Matched & 28.371 & 28.668 & -1.3 & 92.4 & -0.18 & 0.859 \\
\hline \multirow[t]{2}{*}{ kmhosp } & Unmatched & 9.748 & 9.812 & -0.7 & & -0.10 & 0.918 \\
\hline & Matched & 9.748 & 9.756 & -0.1 & 87.9 & -0.01 & 0.990 \\
\hline \multirow[t]{2}{*}{ kmu5 } & Unmatched & 3.785 & 4.645 & -13.0 & & -1.90 & 0.057 \\
\hline & Matched & 3.785 & 3.720 & 1.0 & 92.4 & 0.16 & 0.874 \\
\hline \multirow[t]{2}{*}{ acc4 } & Unmatched & 0.179 & 0.172 & 1.9 & & 0.28 & 0.778 \\
\hline & Matched & 0.179 & 0.171 & 2.1 & -7.6 & 0.29 & 0.771 \\
\hline \multirow[t]{2}{*}{$\operatorname{acc} 5$} & Unmatched & 0.104 & 0.102 & 0.5 & & 0.08 & 0.938 \\
\hline & Matched & 0.104 & 0.117 & -4.5 & -748.9 & -0.62 & 0.536 \\
\hline acc11 & Unmatched & 0.149 & 0.115 & 10.2 & & 1.50 & 0.135 \\
\hline & Matched & 0.149 & 0.133 & 4.6 & 54.3 & 0.63 & 0.527 \\
\hline acc12 & Unmatched & 0.086 & 0.191 & -30.8 & & -4.45 & 0.000 \\
\hline & Matched & 0.086 & 0.103 & -5.1 & 83.6 & -0.83 & 0.406 \\
\hline dove & Unmatched & 0.530 & 0.431 & 20.0 & & 2.93 & 0.004 \\
\hline & Matched & 0.530 & 0.543 & -2.6 & 87.0 & -0.36 & 0.715 \\
\hline Balance & mmary statis & & & & & & \\
\hline & Sample & Pseudo $\mathrm{R}^{2}$ & LR chi2 & $\mathrm{p}>\mathrm{chi} 2$ & & & \\
\hline & Unmatched & 0.112 & 133.78 & 0.000 & & & \\
\hline & Matched & 0.004 & 4.49 & 1.000 & & & \\
\hline
\end{tabular}

\section{(cc) $\mathrm{BY}$}

This work is licensed under a Creative Commons Attribution 3.0 License. 